\title{
Infleunce of Body Mass Index (BMI) on Outcome of Colon Cancer in Relationships with Other Clinicopathological
}

\section{Factors}

\author{
Ahmad A Mubarak $(\mathrm{PhD})^{1}$ and Alaa $\mathrm{H}$ Mustaf(MSc) ${ }^{2}$ \\ ${ }^{1}$ Consultant oncologist,Baghdad Medical City, Oncology Teaching Hospital, Iraq \\ ${ }^{2}$ Consultant oncologist,Baghdad Medical City, Oncology Teaching Hospital, Iraq \\ Correspondence Address: \\ Alaa H Mustaf \\ Consultant oncologist,Baghdad Medical City, Oncology Teaching Hospital, Iraq \\ email: alaa.h.almustaf@gmail.com
}

Received: 26 May 2021

Accepted: 15 July 2021

Published: 25 December 2021

Diyala Journal of Medicine 2021:21(2): 52-63

\begin{abstract}
Background: Colon cancer is the third most common cancer. High (BMI) contributes hazardously for several types of malignancies including colon cancer while the effect of BMI as a prognostic factor is poorly defined.

Objective: Demonstrating the influence of increasing (BMI) on colon cancer recurrence.

Patients and Methods: Case-control study involved a sample of 312 patients and 131 patients were excluded from this study and only 181 patients of colon cancer are included in the study with stage 2 and 3 who did underwent a surgical operation and received adjuvant chemotherapy recruited from an oncology teaching hospital, Al Jawad oncology center (Alkadhemiya hospital) and Babylon Oncology center.

Results: The study involved 181 patients of colon cancer patients with mean age of 56.25 \pm 11.74 years the highest proportion of study patients $(90.6 \%)$ were aged more than $40 \mathrm{yrs}$ with a male to female ratio (1.2:1). Overweight patients constituted $39.2 \%$ and obese $23.8 \%$ and normal body weight $37 \%$. In this study majority of tumors are ulcerating for about $72.5 \%$ and sigmoid and left side colon was the most common site of the tumor in about 53\% with stage three is a most common type. Regarding recurrence, $54.1 \%$ of study patients have recurrence, and the majority of the $41.8 \%$ occurs between 1-3years after primary tumors diagnoses and treatment with a high prevalence of recurrence was seen in obese patients $(74.4 \%)$ with a significant association between prevalence of recurrence and increasing BMI. In this study, $61.2 \%$ of patients with lymphovascular invasion have recurrences of malignancy with significant associations between recurrences and LVIe. Also more than $50 \%$ of patient older than 40years got recurrences with significant associations between recurrences with age of patients. In this study we take the effect of each clinicopathological feature on the outcome of
\end{abstract}


colon cancer and then to excluded its effect by logistic regression to see the effect of only BMI on the outcome of colon cancer.

Conclusion: Increase body mass index is associated with increase recurrence of colon cancer Keywords: Colon cancer recurrence, body mass index, Clinicopathological Factors

DOI: https://doi:10.26505/DJM.21026060526 , ()Authors, 2021, College of Medicine, University of Diyala.

This is an open access article under the CC BY 4.0 license (http://creativecommons.org/licenses/by/4.0/)

\section{Introduction}

Colon cancer is the fourth leading cause of cancer-related death worldwide accounting for about 1400000 new case and 700000 deaths and United States represent the second leading cause of death[1]. Just in 2010, it is account $10 \%$ of cancer mortality[2].Age affects the incidence more than other factors, and the sporadic colon tumors increases dramatically above the ages of 45 to 50 years for all groups.

In almost all countries, age-standardized incidence rates are less for women than for men. Although the incidence has decreased overall, presumably due to aggressive screening of the population older than age 50 years, there has been a dramatic increase in younger patients[3].

Iraqi cancer registry (ICR) revealed incidence rate $(3.2$ - 4) per 100,000 population from 2011 - 2015 comparative study of ICR during 30yrs (1965-1994) show increase incidence in Iraq from 25\%-50\%. with incidence of about $2.6 \%$ compared to 6$13 \%$ in the developed countries and 17$51.1 \%$ in industrialized nations and rank sixth among most common 10 cancers in Iraq [4]. Global cancer observation GLOBOCAN 2018 publicated top 5 cancers includes (breast, lung, leukaemia, Bladder Colorectum cancers).
Obesity and decrease physical activity: There are now multiple studies that demonstrate an association between obesity, exercise, and colon cancer.

Diabetes and HbA1c concentrations are associated with an increased risk of cancers[5].The role of insulin and its associated growth factors and binding proteins had implicated in colon carcinogenesis. A recent analysis of two large American cohorts of health sector workers where detailed dietary and physical activity assessments revealed a correlation between high glycemic load, fructose, and sucrose ingestion, and tumor risk[6]. Healthy lean body mass individuals seem to have lower mortality rates from other causes too especially cardiovascular events[7].

In obesity, immune cells such as macrophages, $T$ cells and $B$ cells infiltrate the white adipose tissue Activation of these cells causes local and systemic increases of inflammatory cytokines, such as tumour necrosis factor (TNF) and interleukin (IL)-6 which play an important role for tumor initiation $[8,9]$. Increased intra-abdominal adipose tissue (IAAT) contributes to initiation of colon cancer in multi-step process starting from activated colonocyte proliferation rate which increases the likelihood of mutations caused by DNA 
replication errors or large scale chromosomal abnormalities, thereby generating neoplastic polyps that can undergo malignant .suggests that hyperinsulinemia and perturbations in the insulin-like growth factor (IGF) axis may be important mechanisms for increased risk of colon cancer, and such factors may also consequence in returning cancer and death[11,12].

Aim of study protruding the relationship of overweight (high BMI) and recurrence of colon cancer.

\section{Patients and Methods}

Total numbers of patients included in the study were 181 . The data of the study were collected retrospectively from January 2015 to December 2018 and prospectively from January 2019 till October 2019 from Oncology teaching hospital and Babylon oncology centre and Al-JAWAD oncology centre. The variables which have effects on colon cancer recurrences, were also included in the study to show their effects on colon cancer recurrence.

\section{Study Population \\ Inclusion Criteria:}

1- Patient age (35-70)years.

2- Tumour stage 2 and 3

3- Normal body weight and overweight and obese at presentation before surgery

4-Patient completed surgery and chemotherapy and regular follow-up

\section{Exclusion Criteria}

1-Denovo metastasis colon cancer

2-Stage 1 cancer

3-Comorbidity -patient suffering from severed comorbid disease that have effect on body weight like diabetes mellitus and thyroid disease

4-Strict diet for any cause or anorexia
5- Inoperable patients or patients refuse surgery for any cause

6- Discontinue adjuvant chemotherapy

7- Second or more primary cancers

8- Familial cause of colon cancer

Study Design: Body mass index was measured from all patients included in this study before first diagnoses of colon tumor (before surgical operation and chemotherapy) to see the effect of weight on recurrence of cancer. the collected data included:

1-name ,age ,sex,residence and accupation

2-date of diagnoses of colon cancer

3-date and type of surgery

4-date of first chemotherapy

5-BMI before surgery . Patients were divided according to BMI into ( normal body weight:20-24.9 $\mathrm{kg} \backslash \mathrm{m} 2$, overweight:25$30 \mathrm{~kg} \backslash \mathrm{m} 2$. and obese when its more than $30 \mathrm{~kg}^{2} \mathrm{~m}^{2}$ ).

6- performance state and bowel obstruction or perforation at presentation.

7-tumour location and pathological macroscopical feature of malignancy.

8-differentiation and depth of penetration and lymph node status of tumours

9-recurrences if present and time from diagnoses to recurrence

\section{Statistical analysis}

The data were analyzed using Statistical Package for Social Sciences (SPSS) version 25. The data were presented as mean, standard deviation and ranges. Categorical data were presented by frequencies and percentages. Independent t-test (two tailed) was used to compare BMI with recurrence of malignancy. Chi square test was used to assess the association between prevalence of recurrence of malignancy and certain 
information. Logistic regression analysis* and p-value* were mention in appendex.

\section{Results}

The total number of study patients was 181 , who diagnosed colon cancer.
General characteristics: Below are the figures and tables that demonstrate the distribution of patients according to age, gender, tumor characterstics, and body mass index.

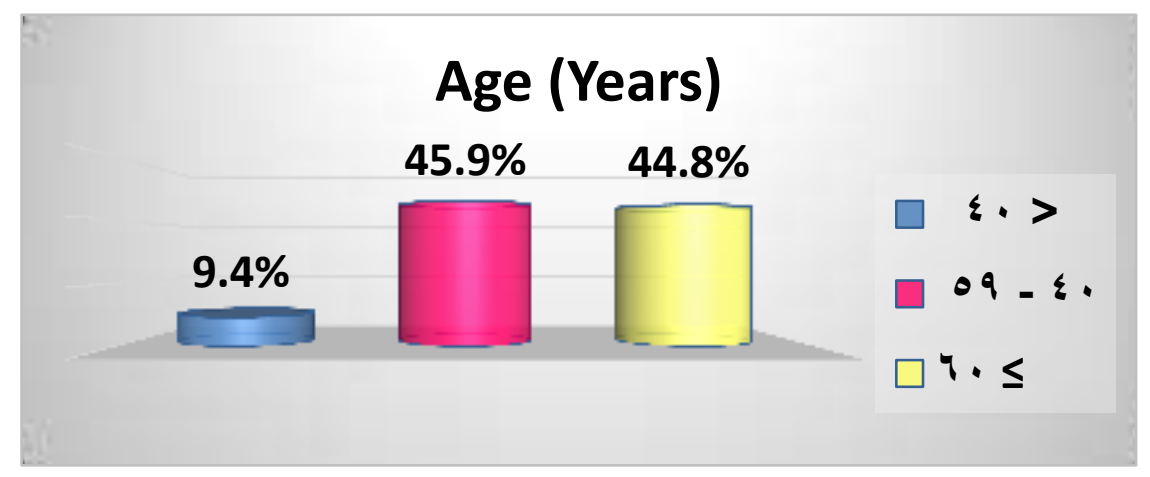

Figure (1): Distribution of study patients by age

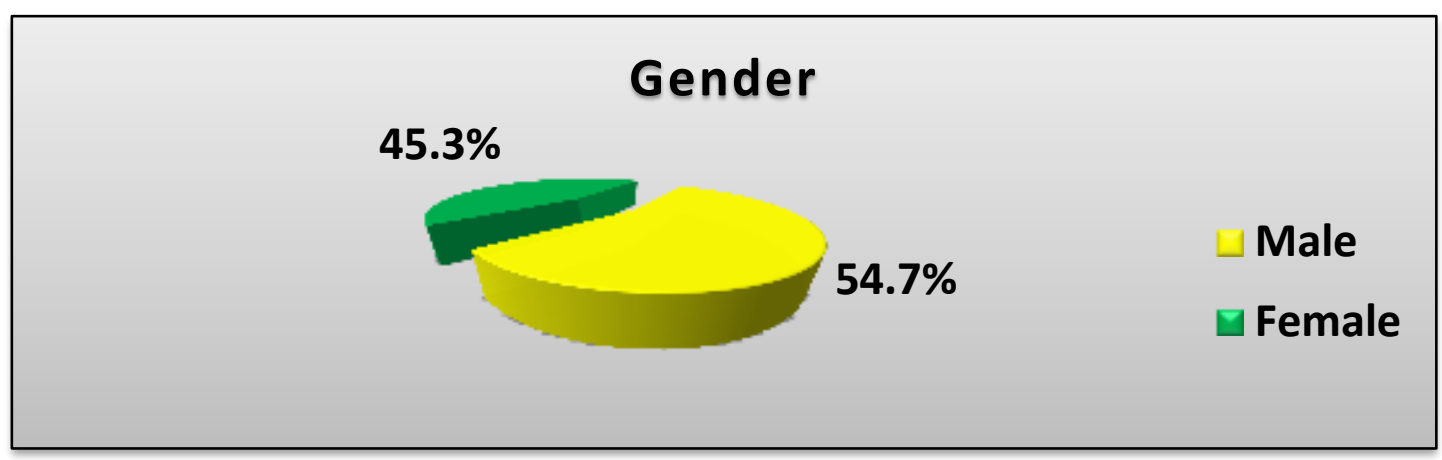

Figure (2): Distribution of study patients by gender 
Infleunce of Body Mass Index (BMI) on Outcome of Colon Cancer in Relationships with Other Clinicopathological Factors

Table (1): Distribution of study patients by tumor characteristics

\begin{tabular}{|c|c|c|}
\hline Tumor characteristics & No. $(n=181)$ & Percentage $(\%)$ \\
\hline \multicolumn{3}{|c|}{ Macroscopic Pathological Feature $\quad n=142$} \\
\hline Ulcerating & 103 & 72.5 \\
\hline Polypoid & 37 & 26.1 \\
\hline Annular & 2 & 1.4 \\
\hline \multicolumn{3}{|l|}{ Tumor Location } \\
\hline Sigmoid and left colon & 96 & $53 \%$ \\
\hline transverse colon & 61 & $33 \%$ \\
\hline right colon & 24 & $14 \%$ \\
\hline \multicolumn{3}{|l|}{ Differentiation } \\
\hline Well & 15 & 8.3 \\
\hline Moderate & 160 & 88.4 \\
\hline Poor & 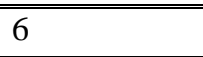 & 3.3 \\
\hline \multicolumn{3}{|l|}{ Tumor Status } \\
\hline $\mathrm{T} 1$ & 3 & 1.7 \\
\hline T2 & 23 & 12.9 \\
\hline T3 & 112 & 62.9 \\
\hline T4 & 40 & 22.5 \\
\hline \multicolumn{3}{|l|}{ Lymph Node } \\
\hline Negative & 51 & 28.7 \\
\hline $1-4$ & 124 & 69.7 \\
\hline$\geq 5$ & 3 & 1.6 \\
\hline \multicolumn{3}{|c|}{ Stage of Tumor $n=172$} \\
\hline 2 & 76 & 44.2 \\
\hline 3 & 96 & 55.8 \\
\hline \multicolumn{3}{|l|}{ Lympho-vascular Invasion } \\
\hline YYes & 1116 & 64.1 \\
\hline No & 65 & 35.9 \\
\hline
\end{tabular}

Table (2): Distribution of patient according to BMI leve

\begin{tabular}{|c|c|c|}
\hline Variable & No. $(n=181)$ & Percentage (\%) \\
\hline \multicolumn{3}{|l|}{$\overline{\text { BMI Level }}$} \\
\hline Normal & 67 & 37.0 \\
\hline Over weight & 71 & 39.2 \\
\hline Obese & 43 & 23.8 \\
\hline
\end{tabular}

\section{Recurrence of malignancy}

It was noticed that $54.1 \%$ (98patient) of study patients got recurrence of malignancy and the majority occurred between $(-3)$ years as shown in Table (3). 
Infleunce of Body Mass Index (BMI) on Outcome of Colon Cancer in Relationships with Other Clinicopathological Factors

Table (3): Distribution of recurrent cases by duration until recurrence

\begin{tabular}{|c|c|c||}
\hline $\begin{array}{c}\text { Duration until recurrence } \\
\text { (Years) }\end{array}$ & $\begin{array}{c}\text { No. }(\mathbf{n}= \\
\mathbf{9 8})\end{array}$ & Percentage (\%) \\
\hline$<\mathbf{1}$ & 38 & 38.8 \\
\hline $\mathbf{1}-\mathbf{3}$ & 41 & 41.8 \\
\hline$>\mathbf{3}$ & 19 & 19.4 \\
\hline
\end{tabular}

Table (4) shows the correlations between no significant correlation between BMI and BMI and duration until recurrence. There was during until

recurrence.

Table (4): Correlations between BMI and duration of recurrence

\begin{tabular}{|l||l||l|}
\hline \multirow{3}{*}{ BMI $\left(\mathrm{Kg} / \mathrm{m}^{2}\right)$} & $\mathrm{R}^{*}$ & $\begin{array}{l}\text { P-value } \\
0.129\end{array}$ \\
\cline { 2 - 3 } & 0.156 & \\
\hline
\end{tabular}

*Correlation Coefficient $\mathrm{R}$ value definition in appendix

Table (5) shows the association between significantly associated with the BMI. There prevalence of recurrence of malignancy and is a non-significant association between general patient characteristics. A higher recurrent tumors with the other general recurrence was seen in obese patients characteristics (74.4\%), and an increase age was a

Table (5): Association between prevalence of recurrence of malignancy and general patient characteristics

\begin{tabular}{|c|c|c|c|c|}
\hline & $\begin{array}{l}\text { Yes }(\%) \\
n=98\end{array}$ & $\begin{array}{l}\text { No (\%) } \\
n=83\end{array}$ & & \\
\hline \multicolumn{5}{|l|}{ Age (Years) } \\
\hline$<40$ & $12(70.6)$ & $5(29.4)$ & $17(9.4)$ & \multirow[b]{2}{*}{0.0015} \\
\hline$\geq 40$ & $86(52.5)$ & $78(47.5)$ & $164(90.6)$ & \\
\hline \multicolumn{5}{|l|}{ Gender } \\
\hline Male & 55 (55.6) & $44(44.4)$ & $99(54.7)$ & \multirow{2}{*}{0.675} \\
\hline Female & $43(52.4)$ & 39 (47.6) & $82(45.3)$ & \\
\hline \multicolumn{5}{|l|}{ BMI Level } \\
\hline Normal & $27(40.3)$ & $40(59.7)$ & 67 (37.0) & \multirow{3}{*}{0.002} \\
\hline Over weight & 39 (54.9) & $32(45.1)$ & $71(39.2)$ & \\
\hline 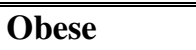 & 32 (74.4) & "11(25.6) & $43(23.8)$ & \\
\hline
\end{tabular}

Table (6) in comparison between patients according to recurrence of malignancy by BMI, we noticed that the mean of BMI in patients with recurrence of malignancy was significantly higher than that in patients without recurrence $(28.3$ versus $23.6 \mathrm{Kg} / \mathrm{m} 2$, $\mathrm{P}=0.001)$. 
Table (6): Comparison between patients according to recurrence of malignancy by BMI

\begin{tabular}{|c|c|c|c|}
\hline \multirow{3}{*}{ BMI $\left(\mathrm{Kgbmm}^{2}\right)$} & \multicolumn{2}{|c|}{ Recurrence of Malignancy } & \multirow{2}{*}{ P- Value } \\
\hline & $\begin{array}{l}\text { YES } \\
\text { Mean } \pm \text { SD }\end{array}$ & $\begin{array}{l}\text { NO } \\
\text { Mean } \pm \text { SD }\end{array}$ & \\
\hline & $28.3 \pm 2.1$ & $23.6 \pm 2.3$ & 0.001 \\
\hline
\end{tabular}

Table (7) shows the association between with a significant association $(\mathrm{P}=0.001)$ prevalence of recurrence of malignancy and tumor characteristics. In this study, $62.9 \%$ of between recurring and lymphovascular invasion (LVI), while there were nonpatients with lymphovascular invasion were significant associations with the other tumor complained from recurrence of malignancy characteristics.

Table (7): Association prevalence of recurrence of malignancy and tumor characteristics

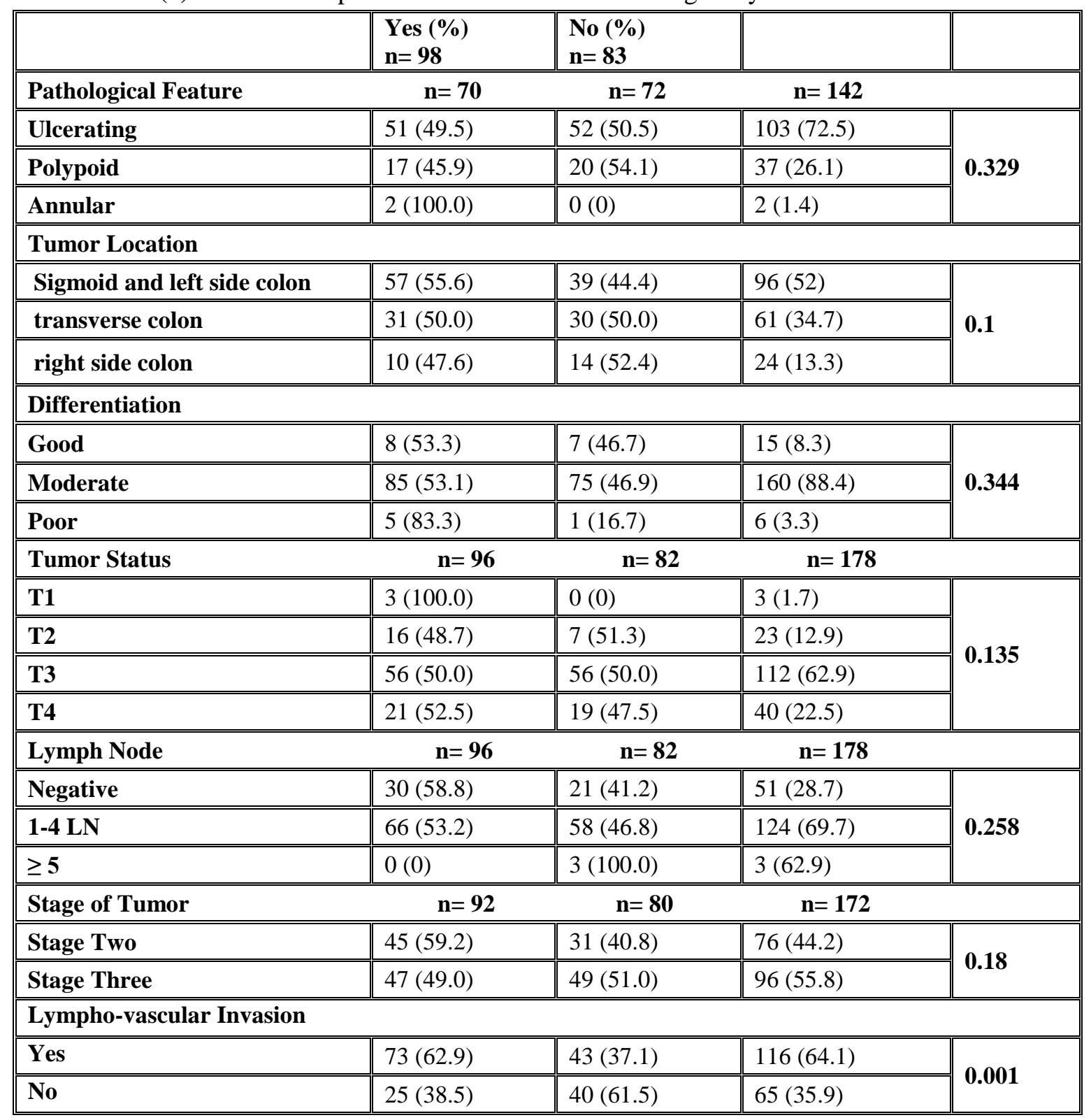


Table (8) Obesity, age and lymphovascular independent risk factors $(\mathrm{OR}=6.7, \mathrm{OR}=7.4$ invasion were found to be significant and $\mathrm{OR}=3.2$ respectively).

Table (8): Logistic regression analysis for association of various risk factors with prevalence of recurrence of malignancy

\begin{tabular}{|c|c|c|c|}
\hline BMI Level & $\begin{array}{l}\text { Odd's } \\
\text { ratio }\end{array}$ & $\begin{array}{l}95 \% \text { C.I for odd's } \\
\text { ratio }\end{array}$ & $\mathbf{P}$ - Value \\
\hline Obese & 6.7 & $2.46-17.85$ & 0.001 \\
\hline Lympho-vascular Invasion & 3.2 & $1.42-8.91$ & $\mathbf{0 . 0 3 2}$ \\
\hline Age & 7.4 & $2.9-19.23$ & 0.001 \\
\hline
\end{tabular}

\section{Discussion}

In our study we exclude the effects of other clinicopathological feature like(age, gender, stage, lymph node status, type of differentiation, location of tumor, pathological status of tumor, lymphovascular invasion and other features mentioned in the results) on outcome of colon cancer by logistic regression analyses to see the effect of body mass index alone on outcome(recurrence) of colon cancer.

Tumor characteristics: In this study, ulcerating tumors represented the majority $(72.5 \%)$. The majority of tumors of about $(88.4 \%)$ were moderately differentiated.

Our study reveals that $62.9 \%$ were T3( tumor invades through muscularis properia into pericolic tissues) and $69.7 \%$ had $(1-4)$ lymph nodes involvement; and $64.1 \%$ had lymphovascular invasion. Regarding the stage of the tumor, the highest proportion of tumors was in stage three at a rate of $(55.8 \%)$. In our study, the sigmoid and left side colon was the most common site of a tumor in studying patients different results were observed in a study conducted by Bandamiri and colleagues in 2017, as noticed that ( sigmoid segment) of the colon is the most common site of recurrence although it is not significant[13].

Recurrence of malignancy: In our study, nearly half of study patients $(54.1 \%)$ got recurrences of malignancy and $41.8 \%$ of those with recurrence were suffering from recurrences of malignancy after $(1-3)$ years from the initial diagnosis. This is in agreement with Bandamiri et al study that was conducted in 2017, in which the overall five-year recurrence rate was $56.8 \%$ but seems higher from what is reported by previous studies in Iran conducted by Aghili and colleagues in 2010, which observed that rate of late recurrence was $30 \%$ of total recurrences [14].

In our study, it was obvious that there were no statistically significant associations $(\mathrm{P} \geq 0.05)$ between the prevalence of recurrences and gender and significant association with age. According to the results obtained by Fatemi and colleagues in 2015, neither age nor gender was significantly associated with recurrence of CRC after surgery[15]. Furthermore, Age of patients with cancer recurrence in the Micu et al study in 2015, did not differ significantly from 
those without recurrence $(\mathrm{p}=0.08)$, also the difference in gender distribution in the two groups was not statistically significant $(\mathrm{p}=0.4)$.

The degree of differentiation in Micu et al study has statistically significantly influenced the disease-free interval, grade four (G4) being significantly associated with cancer recurrence [16]. Bandamiri in 2017, observed that the age of patients with colon cancer recurrence was significantly higher than those without recurrence $(\mathrm{P}=0.035)$, furthermore, women had a significantly less chance of recurrence $(43.5 \%)$ compared to men $(56.5 \%),(\mathrm{P}=0.041)$ [13]. This finding is consistent with previous studies suggesting a significantly higher risk of recurrence of CRC in older patients, as noticed in Aghili et al study in 2010, and Westberg et al study in 2015[17].

In our study, the highest prevalence of recurrence was seen in obese patients (74.4\%) with a significant association between recurrence of malignancy and BMI level $(\mathrm{P}=0.002)$ mean of $(\mathrm{BMI})$ in patients with recurrence of malignancy was significantly higher than that in patients without recurrence ( 28.3 versus $23.6 \mathrm{Kg} / \mathrm{m}^{2}$ ).

Our result agreed to that conducted by Sinicrope and colleagues in 2013 which noticed that the BMI category was associated significantly with time to recurrence of CRC, they concluded that obesity and underweight status were associated independently with inferior outcomes in patients with colon cancer who received treatment in adjuvant chemotherapy trials. Obese patients had a shorter time to recurrence and worse deathfree survival and overall survival versus normal-weight patients [18].
In contrary to our result, Fatemi and colleagues in their study in 2015 observed that no correlation between BMI and recurrence after surgery in CRC patients as found that the highest prevalence of patients was in BMI level $25-29.9 \mathrm{Kg} / \mathrm{m}^{2}$, the discrepancy in the result can be attributed to a small sample size included in this study, in addition to the positive family history of cases [15]. Furthermore, Meyerhardt and colleagues in their study in 2003, observed that obese women with colon carcinoma $\left(\mathrm{BMI} \geq 30.0 \mathrm{~kg} / \mathrm{m}^{2}\right.$ ) experienced significantly worse overall mortality and a non-significant increase in the risk of disease recurrence and influence of BMI among women was not related to any differences in chemotherapy dose-intensity across categories of BMI.

In our study, a rate of $(62.9 \%)$ of patients with lymphovascular invasion got recurrences of malignancy with a significant association $(\mathrm{P}=0.001)$ between the prevalence of recurrence of malignancy and lymphovascular invasion. Similarity to our result observed in a study conducted by Bandamiri and colleagues in 2017, in which found that lymphovascular invasion was reported significantly less frequently in patients without recurrence (23.6\%), compared to $(53.2 \%)$ in patients who experienced recurrence $(\mathrm{P}<0.001)$. An agreement also observed in a study conducted in 2018 by Yamano that involved 3039 patients with colon cancer who underwent curative surgery, results obtained showed that lymphavascular invasion, venous invasion, and clinical stage were significantly associated with recurrence[19].

In our study, there were no significant associations $(\mathrm{P} \geq 0.05)$ between the 
prevalence of recurrence with pathological features, tumor location, differentiation, tumor status, lymph nodes and stage of the tumor. This is in agreement to Bandamiri et al study in 2017, in which no significant association was found between the risk of recurrence and number of dissected lymph nodes, grade, the proportion of positive lymph nodes, perineural invasion and type of treatment $(\mathrm{P}>0.05$ for all) [13].

Our findings are in contrast with what was reported by Micu and colleagues in their study in 2015, who reported that more lymph node involved by malignancy has a worse prognosis and more chance of recurring colon cancer[20]. Also in Ooki et al study in 2017, who found that higher lymph nodes involved were significantly associated with recurrence of CRC [21] also in the multivariable analyses of Yamano et al study in 2018, factors correlated with an increased risk for recurrence were male sex, emergency surgery, vascular and perineural invasion, and postoperative complications. For each positive node in stage III, the HR increased by 1.02 (95\% CI, 1.01-1.03). The difference observed among above -mentioned studies can be attributed to a variety of factors, as the sample size of each study, kind of surgery performed on each type of tumor, the experience of operating surgeons, type of adjuvant therapy as doing chemotherapy and its regimens, quality of post-surgical care and surveillance applied to study patients.

*Appendix
*correlation coefficient $\mathrm{R}$ value; measure
how strong relationships between two
variable

$1+$ very strong positive relationship
0.01 to 0.2 no or negligible relationship (which represent range of our value in study 0.156(

0 No relationship

*Logistic regression analysis was applied, using recurrence of malignancy as the dependent variable and the variables that were found significant in the binary analysis were included in the model as the independent variables to investigate for the risk factors of recurrence.

*A level of $\mathrm{P}$ - value less than 0.05 was considered significant.

\section{Conclusions}

Increase body mass index and lymphovascular invasion is associated with an increased risk of recurrence of colon cancers. There is no effect of( age, sex, stage, lymph node involved, grade, pathological feature and tumor location) on the recurrence rate of colon cancer.

\section{Recommendations}

Further studies with large samples size and different centers are required to confirm our findings .Decrease body weight to normal BMI may cause decreased incidence of colon cancer and further improve progression-free survival of patients.

Source of funding: This research was funded by ourselves and these is no other funding cover this study or manuscript preparation and publication.

Ethical clearance: Consents documents of patients will be catch up this research with full information about patient's colon cancer was mentioned. This study was approved by medical ethics committee of college of medicine , university of Diyala.

\section{Conflict of interest: Nill}




\section{References}

[1] Siegel RL, Miller KD, Jemal A. Cancer statistics, 2018. CA Cancer J Clin 2018;68:730 .

[2]Jemal A, Siegel R, Xu J, et al. Cancer statistics, 2010. CA Cancer J Clin 2010;60(5):277 300.

[3] Davis DM, Marcet JE, Frattini JC, et al. Is it time to lower the recommended screening age for colorectal cancer? JAm Coll Surg 2011;213(3):352-361.

[4]Adil H.ALHumadi .epidemiology of colon and rectal cancers in Iraq. World journal of colorectal surgery . Berkeley Electronic Press 2008 , Volume1 ,Issue

[5 ]Nilsen TI, Vatten LJ. Prospective study of colorectal cancer risk and physical activity, diabetes, blood glucose and BMI: exploring the hyperinsulinaemia hypothesis. $\mathrm{Br} \mathrm{J}$ Cancer2001;84:417-22

[6] Kabat GC, Shikany JM, Beresford SA, et al. Dietary carbohydrate, glycemic index, and glycemic load in relation to colorectal cancer risk in the Women's Health Initiative. Cancer Causes Control. 2008;19(10):1291-1298. doi:10.1007/s10552-008-9200-3

[7] Balhareth A, Aldossary MY, McNamara D. Impact of physical activity and diet on colorectal cancer survivors' quality of life: a systematic review. World J Surg Oncol. 2019;17(1):153. Published 2019 Aug 31. doi:10.1186/s12957-019-1697-2

[8] Xu H, et al. Chronic inflammation in fat plays a crucial role in the development of obesity-related insulin resistance. J. Clin. Invest. 2003;112:1821-1830. doi: 10.1172/JCI200319451

[9] Feuerer M, et al. Lean, but not obese, fat is enriched for a unique population of regulatory $\mathrm{T}$ cells that affect metabolic parameters. Nat. Med. 2009;15:930-939. doi: 10.1038/nm.2002.

[10] Shike M. Body weight and colon cancer. Am J Clin Nutr. 1996;63:442S-444S.

[11] Wei EK, Ma J, Pollak MN, et al. A prospective study of C-peptide, insulin-like growth factor-I, insulin-like growth factor binding protein-1, and the risk of colorectal cancer in women. Cancer Epidemiol Biomarkers Prev. 2005;14:850-5.

[12]Sandhu MS, Dunger DB, Giovannucci EL. Insulin, insulin-like growth factor-I (IGF-I), IGF binding proteins, their biologic interactions, and colorectal cancer. J Natl Cancer Inst. 2002;94:972-80.

[13]Zare-Bandamiri M, Fararouei M, Zohourinia S, Daneshi N, Dianatinasab M. Risk Factors Predicting Colorectal Cancer Recurrence Following Initial Treatment: A 5year Cohort Study. Asian Pac J Cancer Prev. 2017;18(9):2465-70

[14] Aghili M, Izadi S, Madani H, Mortazavi $\mathrm{H}$. Clinical and pathological evaluation of patients with early and late recurrence of colorectal cancer. Asia-Pacific journal of clinical oncology. 2010;6(1):35-41.

[15]Fatemi SR, Pourhoseingholi MA, Asadi F, Vahedi M, Pasha S, Alizadeh L, et al. Recurrence and Five -Year Survival in Colorectal Cancer Patients After Surgery. Iran J Cancer Prev. 2015;8(4):e3439-e.

[16] Micu B, Micu C, Dina L, Andercou O, Constantea N. Assessment of clinical and pathological prognostic factors for colorectal cancer recurrence after surgery. Human and Veterinary Medicine. 2015;7:47-54. [17]Westberg K, Palmer G, Johansson H, Holm T, Martling A. Time to local recurrence as a prognostic factor in patients with rectal cancer. European Journal of 
Surgical Oncology (EJSO). 2015;41(5):659-

66.

[18]Sinicrope FA, Foster NR, Yothers G, Benson A, Seitz JF, Labianca R, et al. Body mass index at diagnosis and survival among colon cancer patients enrolled in clinical trials of adjuvant chemotherapy. Cancer. 2013;119(8):1528-36.

[19]Yamano T, Yamauchi S, Tsukamoto K, Noda M, Kobayashi M, Hamanaka M, et al. Evaluation of appropriate follow-up after curative surgery for patients with colorectal cancer using time to recurrence and survival after recurrence: a retrospective multicenter study. Oncotarget. 2018;9(39):25474-90. [20]Micu B, Micu C, Dina L, Andercou O, Constantea N. Assessment of clinical and pathological prognostic factors for colorectal cancer recurrence after surgery. Human and Veterinary Medicine. 2015;7:47-54

[21]Ooki A, Akagi K, Yatsuoka T, Asayama M, Hara H, Nishimura Y, et al. Lymph node ratio as a risk factor for recurrence after adjuvant chemotherapy in stage III colorectal cancer. Journal of Gastrointestinal Surgery. 2017;21(5):867-78. 